\title{
Chemical Profiling of Xueshuan Xinmaining Tablet by HPLC and UPLC-ESI-Q-TOF/MS
}

\author{
Ya-Xin Han, ${ }^{1}$ Peng-Fei Wang, ${ }^{2,3}$ Meng Zhao, ${ }^{2,4}$ Liang-Mian Chen, ${ }^{2}$ \\ Zhi-Min Wang, ${ }^{2}$ Xiao-Qian Liu, ${ }^{2}$ Hui-Min Gao $\mathbb{D}^{2},{ }^{2}$ Mu-Xin Gong $\mathbb{D}^{1}{ }^{1} \mathrm{Hui} \mathrm{Li}{ }^{2}$ \\ Ji-Zhong Zhu, ${ }^{5}$ and Chuan-Gui Liu ${ }^{5}$ \\ ${ }^{1}$ School of Traditional Chinese Medicine, Capital Medical University, Beijing 100069, China \\ ${ }^{2}$ Institute of Chinese Materia Medica, China Academy of Chinese Medical Sciences, National Engineering Laboratory for \\ Quality Control Technology of Chinese Herbal Medicine, Beijing 100700, China \\ ${ }^{3}$ Tianjin University of Traditional Chinese Medicine, Tianjin 300193, China \\ ${ }^{4}$ College of Pharmacy, Henan University of Traditional Chinese Medicine, Zhengzhou 450008, China \\ ${ }^{5}$ Jilin Huakang Stock Ltd., Company of Medicines, Dunhua 133700, China
}

Correspondence should be addressed to Hui-Min Gao; huimin_gao@126.com and Mu-Xin Gong; gongmuxin@126.com

Received 18 April 2018; Accepted 26 September 2018; Published 21 October 2018

Academic Editor: Chang G. Son

Copyright ( 2018 Ya-Xin Han et al. This is an open access article distributed under the Creative Commons Attribution License, which permits unrestricted use, distribution, and reproduction in any medium, provided the original work is properly cited.

\begin{abstract}
Xueshuan Xinmaining Tablet (XXT) is a widely used traditional Chinese medicine for the treatment of stroke, chest pain, coronary heart disease, and angina pectoris caused by blood stasis. Having a multiple-component preparation, it is still far from meeting the requirements of modernization and standardization because its detailed chemical basis and action mechanism have not been clarified. In this work, the different batches of XXT samples were analyzed by HPLC and the typical sample was analyzed by UPLC-ESI-Q-TOF/MS to understand its chemical profiling. As a result, 77 chromatographic peaks were detected, among which 63 constituents were identified or tentatively characterized based on the comparison of retention time and UV spectra with authentic compounds as well as by summarized MS fragmentation rules and matching of empirical molecular formula with those of published components. This is the first systematic report on the chemical profiling of the commercial XXT products, which provides the sufficiently chemical evidence for the global quality evaluation of XXT products.
\end{abstract}

\section{Introduction}

Xueshuan Xinmaining Tablet (XXT) is a widely used traditional Chinese medicine for the treatment of stroke, chest pain, coronary heart disease, and angina pectoris caused by blood stasis [1]. It is prepared from ten raw materials, including Chuanxiong (Chuanxiong rhizoma), Huaihua (Sophorae flos), Danshen (Salviae miltiorrhizae radix et rhizoma), Shuizhi (Hirudo), Maodongqing (Hairy holly root), Rengong Niuhuang (Bovis calculus artifactus), Rengong Shexiang (Moschus artifactus), Renshen Jingye Zongzaogan (Total ginsenoside of ginseng stems and leaves), Bingpian (Borneolum syntheticum), and Chansu (Bufonis venenum) [2]. Nowadays, several qualitative analyses have been reported concerning volatile constituents by GC-MS [3] and chemical fingerprints by HPLC-ELSD [4] and UPLC-PDA [5]. However, having a multiple-component preparation, it is still far from meeting the requirement of modernization and standardization because its complicated ingredients lead to difficulty in clarifying therapeutic material basis, establishing quality control strategy, or selecting chemical markers for pharmacokinetic study.

Ultraperformance liquid chromatography coupled with electrospray ionization tandem quadrupole time-of-flight mass spectrometry (UPLC-ESI-Q-TOF/MS) has become one of the most effective tools for the on-line structural elucidation of multiple components of TCM, owing to its characteristics of accurate mass measurement, high resolution, and excellent sensitivity. $\mathrm{MS}^{\mathrm{E}}$ (E represents collision energy) technology provides an automated strategy to decrease 
analysis time and maximize duty cycles by using parallel alternating scans at low collision energy in the collision cell to obtain precursor ion information or at high collision energy to obtain accurate full-scan mass fragment, precursor ion, and neutral loss information. Therefore, both precursor and fragmentation data in exact mass mode were collected in a single run. This method has been proved to provide excellent chromatographic and MS efficiencies in the previous publications [6]. In the present investigation, a combination of HPLC and UPLC-Q-TOF/MS analyses was employed to find out and identify the common chemical profile in various batches of XXT samples. A total of 63 constituents were identified or tentatively characterized based on the comparison with reference substances, on-line UV spectra, and the fragmentation rules.

\section{Materials and Methods}

2.1. Materials and Reagents. Ten batches of Xueshuan Xinmaining Tablet (Lot. 160904, 160905, 161001-161008) were provided by Jilin Huakang Stock Ltd., Company of Medicines (Jilin, China). Reference substances of sodium danshensu (Lot. ZZS17032207), rosmarinic acid (Lot. ZZS17032201), salvianolic acid B (Lot. ZZS17032203), dihydrotanshinone (Lot. ZZS17032209), cryptotanshinone (Lot. ZZS17032204), and tanshinone IIA (Lot. ZZS17032206) were purchased from Shanghai ZZBIO Co, (Shanghai, China). Reference substances of neochlorogenic acid (Lot. X-014-140801), isochlorogenic acid B (Lot. Y-069141122-1), and isochlorogenic acid C (Lot. Y-070-140801) were purchased from Chengdu Herbpurify Co. (Chengdu, China). Reference isochlorogenic acid A (Lot. 20130816) were purchased from Shanghai Yuanye Bio-Technology Co. (Shanghai, China). Reference substances of caffeic acid (Lot. 110885-200102), ginsenoside $\mathrm{Rg}_{1}$ (Lot. 110703-201027), ginsenoside $\mathrm{Re}$ (Lot. 110754-200822), ginsenoside $\mathrm{Rb}_{2}$ (Lot. 111715-200802), ginsenoside $\mathrm{Rb}_{3}$ (Lot. 111686-201002), 20Sginsenoside $\mathrm{F}_{1}$ (Lot. 111763-200601), 20S-ginsenoside $\mathrm{F}_{2}$ (Lot. 111764-200601), 20S-ginsenoside $\mathrm{Rh}_{2}$ (Lot. 111748-200501), cinobufagin (Lot. 110803-200605), and resibufogenin (Lot. 110718-200507) were purchased from the National Institutes for Food and Drug Control (Beijing, China). Gamabufotalin, bufotalin, and bufalin were purified from the fresh toad venom (the purity of gamabufotalin was over $92.9 \%$ and the purity of bufotalin and bufalin was over $98 \%$ based on the area normalization by HPLC analysis). Ginsenoside Rd, chlorogenic acid, rutin, quercetin, protocatechualdehyde, ursodesoxycholic acid, and chenodeoxycholic acid were from the collection of our laboratory and their purities were over $98 \%$. The structures of all reference compounds were shown in Figure 1.

HPLC grade acetonitrile and formic acid (Fisher, Fair Lawn, NJ, USA) and ultrapure water were used. All other chemical reagents were of analytical grade from Beijing Chemical Corporation (Beijing, China).

2.2. Reference Solution Preparation. Stock solution with a concentration of about $0.1 \mathrm{~g} \cdot \mathrm{L}^{-1}$ was prepared by dissolving an accurately weighed amount of each reference substance in methanol.

\subsection{Sample Preparation}

2.3.1. XXT Sample. $1.0 \mathrm{~g}$ (about 2.5 tablets) of pulverized XXT sample was extracted with methanol $(25 \mathrm{~mL})$ by ultrasonication $(200 \mathrm{w}, 53 \mathrm{kHz})$ for $30 \mathrm{~min}$ at room temperature, and the extract was centrifuged for $5 \mathrm{~min}$ at $3000 \mathrm{rpm}$. The supernatant was evaporated at $80^{\circ} \mathrm{C}$ and the residue was dissolved with aqueous methanol $\left(\mathrm{MeOH}-\mathrm{H}_{2} \mathrm{O}, 9: 1\right)$. The obtained solution was centrifuged for $5 \mathrm{~min}$ at $12000 \mathrm{rpm}$. A volume of $10 \mu \mathrm{L}$ of the supernatant was used for HPLC analysis.

$1 \mathrm{ml}$ of the sample solution for HPLC analysis was diluted to a volume of $10 \mathrm{~mL}$ and used for UPLC-ESI-Q-TOF/MS analysis.

2.3.2. Raw Materials. The ethanolic and aqueous extracts of individual herb (Danshen, Maodongqing, Shuizhi, Chuanxiong, and Huaihua) were prepared according to the manufacturing processes of XXT (Figure S1) described in the current Chinese Pharmacopoeia [2]. The ethanolic and aqueous extracts along with Rengong Shexiang, Rengong Niuhuang, Renshen Jingye Zongzaogan, Bingpian, and Chansu were dissolved with aqueous methanol solution $\left(\mathrm{MeOH}-\mathrm{H}_{2} \mathrm{O}, 9: 1\right)$ according to the method described in Section 2.3.1 and used for the comparative analyses on the possible contribution from individual herb to general chromatographic profile of XXT samples.

2.4. Qualitative HPLC Analyses of 10 Batches of XXT Samples. The analyses were performed on a Shimadzu HPLC system (Shimadzu, Japan) equipped with an LC-20AT binary pump, a DGU-20A5 degasser, an SIL-20AC autosampler, a CTO20AC column oven, and an SPD-M20A photodiode array detector. The samples were separated on a Waters XTerra $\mathrm{C}_{18}$ column $(4.6 \times 250 \mathrm{~mm}, 5 \mu \mathrm{m})$. The mobile phase consisted of water containing $0.1 \%$ acetic acid (A) and acetonitrile (B) using a gradient elution program as follows: $0 \mathrm{~min}, 10 \% \mathrm{~B} ; 20$ min, 25\% B; $30 \mathrm{~min}, 26 \% \mathrm{~B}$; $45 \mathrm{~min}, 30 \% \mathrm{~B}$; $60 \mathrm{~min}, 60 \% \mathrm{~B}$; and $95 \mathrm{~min}, 80 \% \mathrm{~B}$. The flow rate was $1.0 \mathrm{~mL} \cdot \mathrm{min}^{-1}$ and the column temperature was $30^{\circ} \mathrm{C}$. The PDA detector recorded UV spectra in the range from $190 \mathrm{~nm}$ to $400 \mathrm{~nm}$ and HPLC chromatogram was monitored at $251 \mathrm{~nm}$.

2.5. UPLC-ESI-Q-TOF/MS Analysis. To comprehensively identify the chemical constituents in XXT samples, a UPLCESI-Q-TOF/MS experiment was performed using a Waters Xevo G2-S spectrometer (Waters, America), connected to a Waters UPLC system (Waters, America). The samples were separated on a Waters ACQUITY BEH C 18 column $(2.1 \times 50$ $\mathrm{mm}, 1.7 \mu \mathrm{m})$. The mobile phase consisted of water containing $0.1 \%$ formic acid (A) and acetonitrile (B) using a gradient elution program as follows: $0 \mathrm{~min}, 10 \% \mathrm{~B} ; 4 \mathrm{~min}, 25 \% \mathrm{~B} ; 7$ $\min , 25.6 \% \mathrm{~B} ; 8 \mathrm{~min}, 36 \% \mathrm{~B} ; 14 \mathrm{~min}, 60 \% \mathrm{~B} ; 18 \mathrm{~min}, 80 \%$ $\mathrm{B}$; and $20 \mathrm{~min}, 80 \% \mathrm{~B}$. The mass spectrometer was operated in both positive and negative modes using the following parameters: capillary voltage of $1.8 \mathrm{kV}$, sample cone voltage 


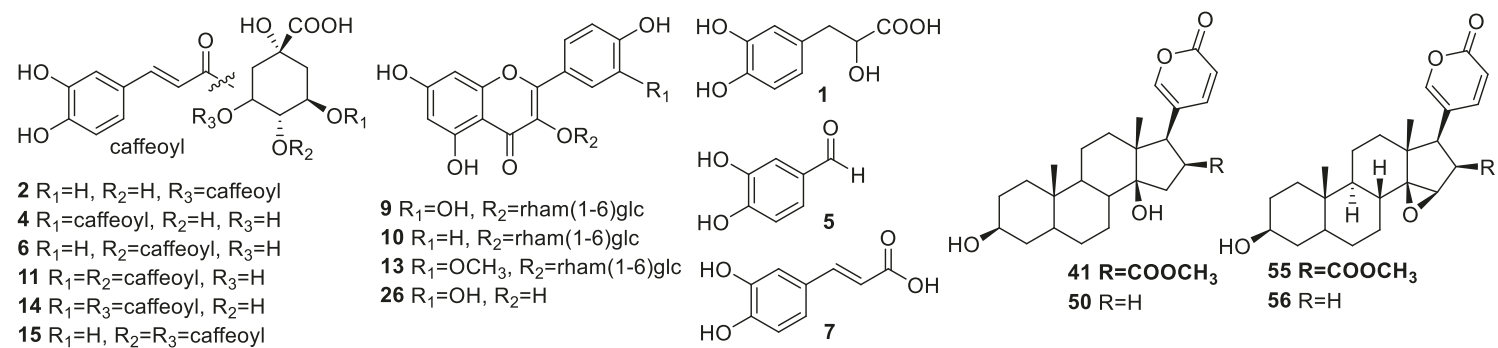

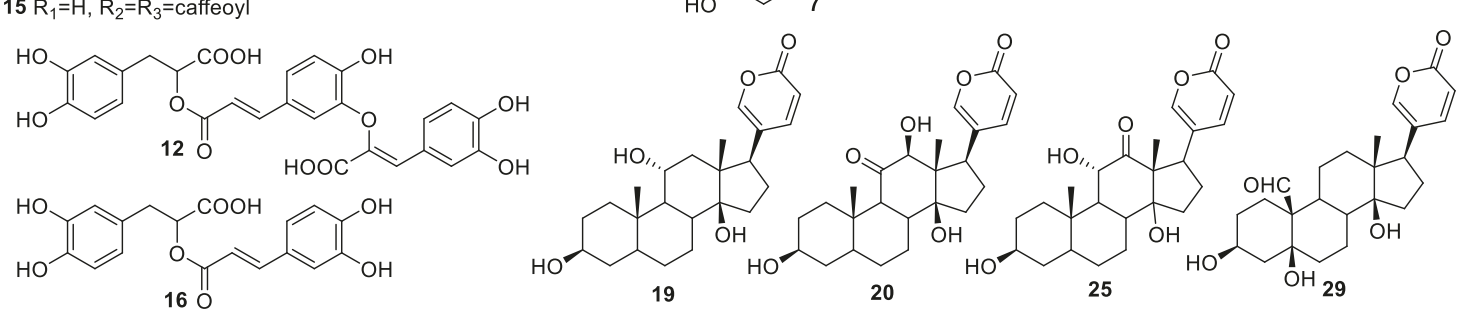<smiles>CCOC(=O)C(Cc1ccc(O)c(O)c1)OC(=O)/C=C/c1ccc(O)c2c1C(C(=O)O)C(c1ccc(O)c(O)c1)O2</smiles><smiles></smiles><smiles>[R]C1(C)CCCc2c1ccc1c2C(=O)C(=O)c2c(C)coc2-1</smiles><smiles>CC(C)C1=Cc2ccc3c(c2C(=O)C1=O)CCCC3(C)C</smiles>

$69 \mathrm{R}=\mathrm{COOCH}_{3}$<smiles>[R]C1CCC2(C)C3CCC(C([R3])(C)CCC=C(C)C)C3C(O)CC2C1(C)C</smiles>

$23 \mathrm{R}_{1}=\mathrm{OH}, \mathrm{R}_{2}=-\mathrm{O}$-glc, $\mathrm{R}_{3}=-\mathrm{O}$-glc $24 \mathrm{R}_{1}=\mathrm{OH}, \mathrm{R}_{2}=-\mathrm{O}-\mathrm{glc}(2-1)$ rham, $\mathrm{R}_{3}=-\mathrm{O}-\mathrm{glc}$ $35 \mathrm{R}_{1}=\mathrm{OH}, \mathrm{R}_{2}=-\mathrm{O}-\mathrm{glc}(2-1) \mathrm{glc}, \mathrm{R}_{3}=-\mathrm{O}-\mathrm{glc}$ $37 \mathrm{R}_{1}=\mathrm{OH}, \mathrm{R}_{2}=-\mathrm{O}-\mathrm{glc}, \mathrm{R}_{3}=-\mathrm{O}-\mathrm{glc}(6-1) \mathrm{glc}$ $40 \mathrm{R}_{1}=\mathrm{OH}, \mathrm{R}_{2}=-\mathrm{O}-\mathrm{glc}(2-1) \mathrm{glc}, \mathrm{R}_{3}=-\mathrm{OH}$ $42 \mathrm{R}_{1}=\mathrm{OH}, \mathrm{R}_{2}=-\mathrm{O}-\mathrm{glc}(2-1) x y l, \mathrm{R}_{3}=-\mathrm{OH}$ $43 \mathrm{R}_{1}=\mathrm{OH}, \mathrm{R}_{2}=-\mathrm{OH}, \mathrm{R}_{3}=-\mathrm{O}-\mathrm{glc}(6-1)$ ara $(\mathrm{p})$ $44 R_{1}=$ O-glc $(2-1) g \mid c, R_{2}=-H, R_{3}=-O-g l c(6-1)$ ara(f) $45 \mathrm{R}_{1}=\mathrm{OH}, \mathrm{R}_{2}=-\mathrm{O}-\mathrm{glc}(2-1)$ rham, $\mathrm{R}_{3}=-\mathrm{OH}$ $46 R_{1}=O-g l c(2-1) g l c, R_{2}=H, R_{3}=-O-g l c(6-1) \operatorname{ara}(p)$ $47 \mathrm{R}_{1}=\mathrm{O}-\mathrm{glc}(2-1) \mathrm{glc}, \mathrm{R}_{2}=-\mathrm{H}, \mathrm{R}_{3}=-\mathrm{O}-\mathrm{glc}(6-1) x y \mid$ $49 \mathrm{R}_{1}=\mathrm{OH}, \mathrm{R}_{2}=\mathrm{OH}, \mathrm{R}_{3}=-\mathrm{O}$-glc $53 \mathrm{R}_{1}=\mathrm{O}$-glc (2-1)glc, $\mathrm{R}_{2}=\mathrm{H}, \mathrm{R}_{3}=-\mathrm{O}$-glc $54 \mathrm{R}_{1}=\mathrm{O}-\mathrm{glc}, \mathrm{R}_{2}=\mathrm{H}, \mathrm{R}_{3}=-\mathrm{O}-\mathrm{glc}(6-1) \mathrm{xyl}$ $61 R_{1}=O-g l c, R_{2}=H, R_{3}=-O-g l c$

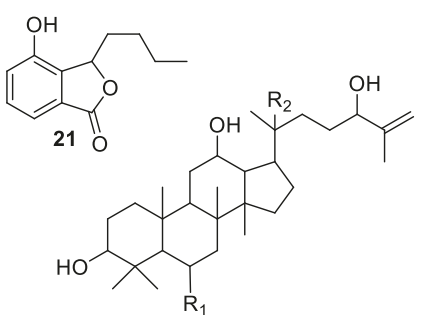
$36 \mathrm{R}_{1}=\mathrm{O}-\mathrm{glc}(2-1) x y l, \mathrm{R}_{2}=\mathrm{O}-\mathrm{glc}$

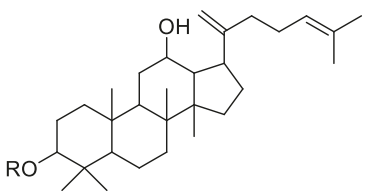

$60 \mathrm{R}=\mathrm{O}-\mathrm{glc}(2-1) \mathrm{glc}$

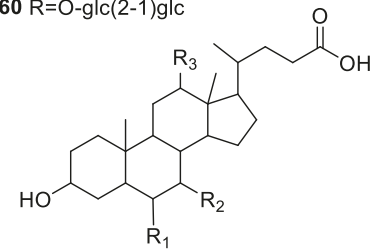

$57 \mathrm{R}_{1}=\mathrm{H}, \mathrm{R}_{2}=$ alpha $-\mathrm{OH}, \mathrm{R}_{3}=$ alpha $-\mathrm{OH}$

$58 \mathrm{R}_{1}=\mathrm{H}, \mathrm{R}_{2}=$ beta- $\mathrm{OH}, \mathrm{R}_{3}=\mathrm{H}$

$67 \mathrm{R}_{1}=$ alpha $-\mathrm{OH}, \mathrm{R}_{2}=\mathrm{H}, \mathrm{R}_{3}=\mathrm{H}$ $74 \mathrm{R}_{1}=\mathrm{O}-\mathrm{glc}, \mathrm{R}_{2}=\mathrm{H}, \mathrm{R}_{3}=\mathrm{OH}$

$70 \mathrm{R}_{1}=\mathrm{H}, \mathrm{R}_{2}=$ alpha $-\mathrm{OH}, \mathrm{R}_{3}=\mathrm{H}$

Figure 1: Structures of the identified compounds in XXT sample. 
of $30 \mathrm{~V}$ (ESI+) or $40 \mathrm{~V}$ (ESI-), source temperature of $120^{\circ} \mathrm{C}$, desolvation temperature of $600^{\circ} \mathrm{C}$, and cone gas flow $50 \mathrm{~L} / \mathrm{h}$. In $\mathrm{MS}^{\mathrm{E}}$ mode, the trap collision energy for the low-energy function was set at $6 \mathrm{eV}$, while the ramp trap collision energy for the high-energy function was set at 25-50 eV. Argon was used as the collision gas for collision-induced dissociation (CID) in $\mathrm{MS}^{\mathrm{E}}$ and $\mathrm{MS}^{2}$ modes. To ensure mass accuracy and reproducibility, the mass spectrometer was calibrated over a range of 100-2000 Da for MS and 50-2000 Da for $\mathrm{MS}^{2}$. Leucine-enkephalin $(\mathrm{m} / z 556.2771$ in positive ion mode; $\mathrm{m} / z 554.2615$ in negative ion mode) was used as an external reference for the LockSpray and was infused at a constant flow of $5 \mu \mathrm{L} \cdot \mathrm{min}^{-1}$. The data were recorded in centroid type during acquisition.

\section{Results and Discussion}

3.1. Qualitative Analyses of XXT Samples by HPLC. In order to obtain better detection of XXT samples, HPLC conditions were optimized. The acetonitrile-water system displayed more powerful separation ability for the main constituents in all samples than the methanol-water system. When organic acid was added to the mobile phase, the symmetry of most chromatographic peaks was improved. Under optimized conditions, ten batches of XXT samples, together with the reference compounds, were examined and their HPLC chromatograms were shown in Figure 2. High similarity in the number, type, and amount of chemical constituents was observed in the HPLC profile of each individual sample, which suggested the chemical consistency of different batches of XXT samples. The characteristic peak 4 (rutin) represents an important active component in XXT sample with a consistently high content, which was chosen as the reference peak for the calculation of the relative retention time ratio and relative peak area ratio of other common chromatographic peaks. For the validation of the assay procedure, the results of precision and repeatability were indicated by RSDs that were less than $4.9 \%(n=6)$ for seventeen peaks (Tables S1 S4). The stability test suggested that these peaks were stable in the sample solution within $24 \mathrm{hr}$ (Tables S5 S6).

To identify the origin of these characteristic peaks from individual raw material, a comparative study was carried out by using various extract of raw materials and XXT samples. Considering the chromatogram recorded at the wavelength of $251 \mathrm{~nm}$, main chromatographic peaks in the HPLC profile were attributed to the following five raw materials: Danshen, Huaihua, Maodongqing, Chuanxiong, and Chansu (Figure S2). The contribution of other raw materials was not manifested, either because of the absence of UV absorption of active compounds or due to the existence of no potent components at the detection condition. More information is expected to further confirm the contribution of each raw material to the general chromatographic profile of XXT sample.

\subsection{Identification of Chemical Constituents in XXT Sample} by UPLC-ESI-Q-TOF/MS. $\mathrm{MS}^{\mathrm{E}}$ analyses in the positive ion mode and negative ion mode were selected for obtaining
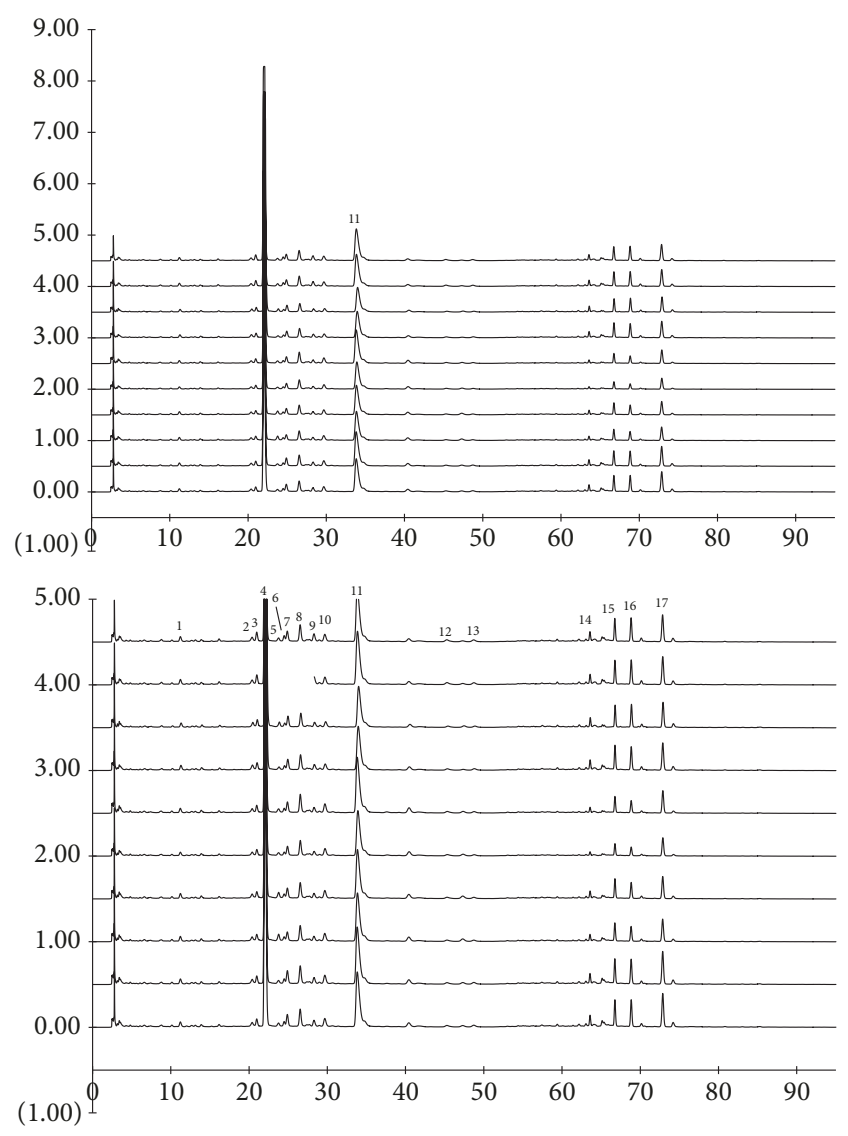

FIgURE 2: HPLC profiles of Xueshuan Xinmaining Tablet samples at $251 \mathrm{~nm}$ (from top to bottom: Lot. 160904, 160905, 161001-161008).

extensive structural information via collision-induced dissociation. For the purpose of determining the optimized $\mathrm{CE}$ to generate fragment ions for structural elucidation and characterization, MS/MS experiments at different CE values were performed. Under optimized parameters, the total ion chromatogram of XXT samples are shown in Figure 3.

The fragmentation behaviors of reference compounds were investigated, and these rules were applied for the structural elucidation of their derivatives with the same basic skeleton. A total of 63 compounds in XXT sample were detected and tentatively characterized by comparing the retention times, MS fragmentation behavior, and literature information. Among these compounds, there were twenty saponins, fifteen phenolic acids, ten quinones, eight steroids, four bile acids, four flavonoids, one amino acid, and one lactone. Their chemical structures are provided in Figure 1. For better understanding of the fragmentation behavior, 63 compounds were divided into several groups and deduced as follows. The chromatographic and mass data of the identified constituents were summarized in Table 1.

Saponin Compounds. Saponin compounds have no UV absorption, but they could be well detected in both positive and negative ionization modes. Usually, the adduct ions such as $[\mathrm{M}+\mathrm{Na}]^{+}(\mathrm{ESI}+)$ or $[\mathrm{M}+\mathrm{HCOO}]^{-}(\mathrm{ESI}-)$ were detected in MS spectrum. In MS/MS spectrum, a series of 


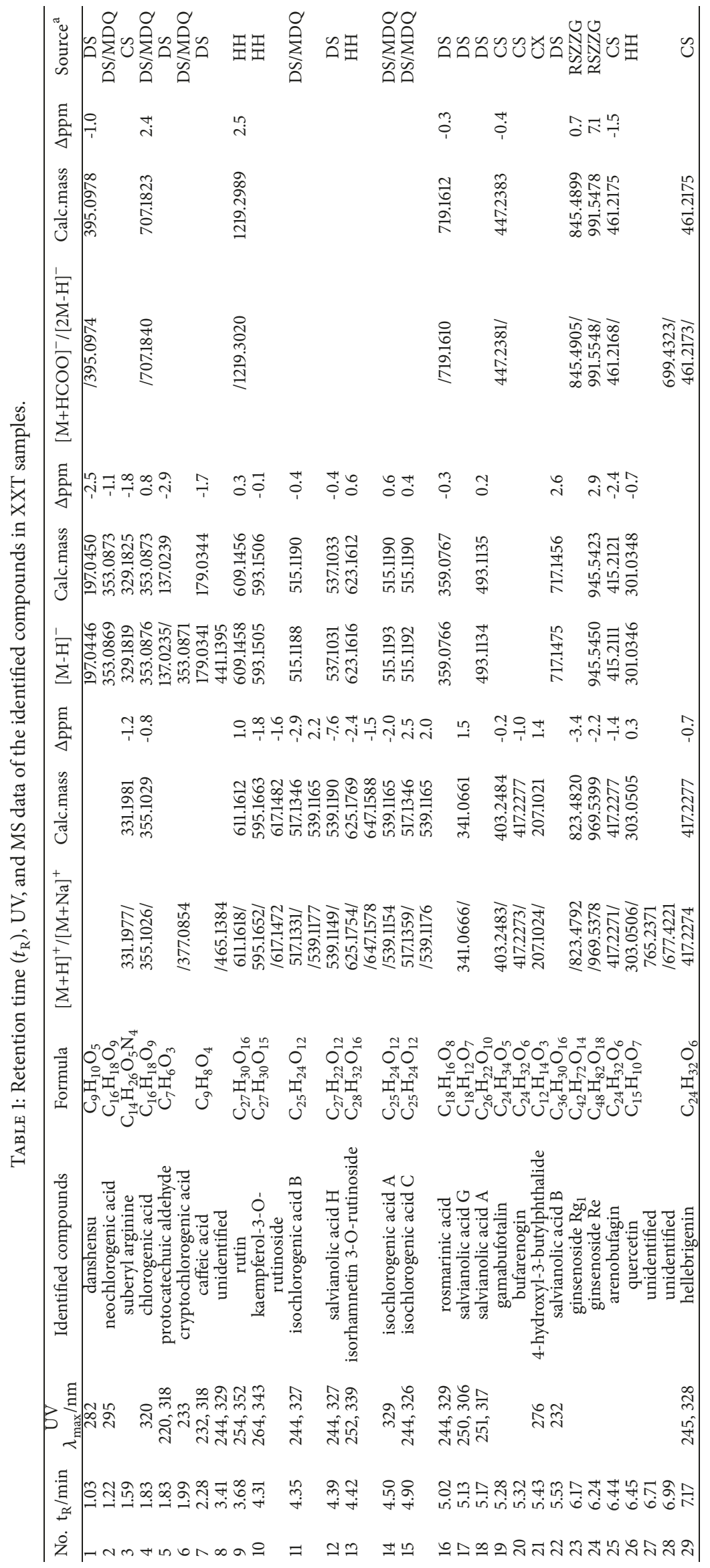




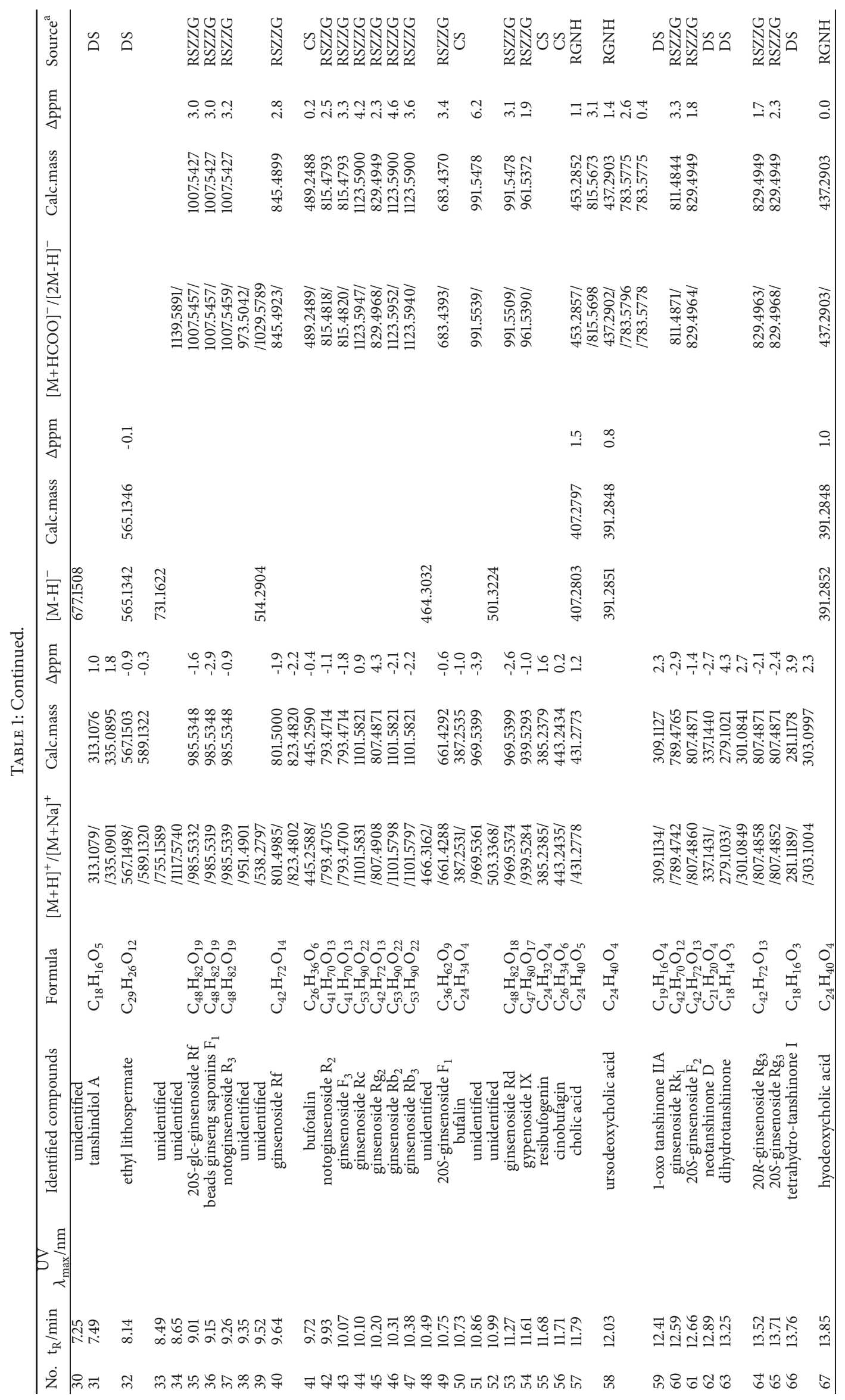




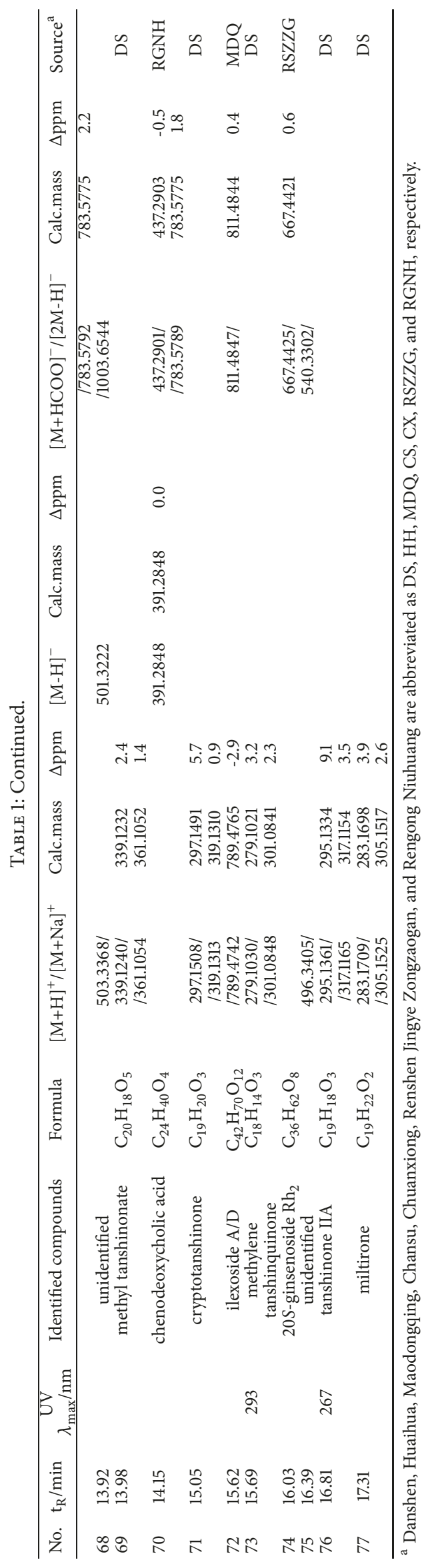




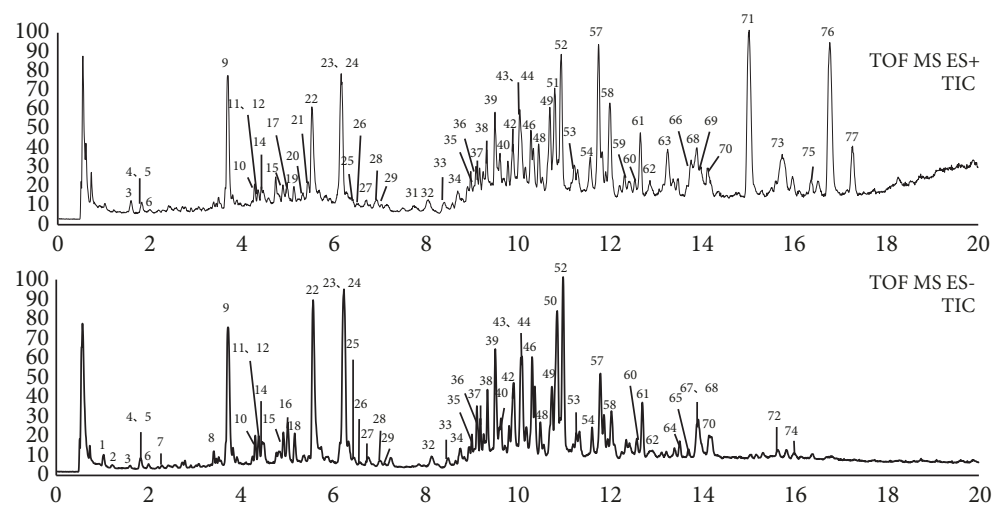

FIgURE 3: TICs of Xueshuan Xinmaining Tablet in the negative and positive modes.

fragmentation ions were observed due to the neutral loss of glucose, rhamnose, arabinose, or xylose (see Figure 4). These fragmentation rules are in accordance with the previous data $[7,8]$. Totally, 20 ginsenoside saponins were identified, and they are deduced from the raw material, total ginsenoside of ginseng stems and leaves. Among the identified saponins, eight compounds $(23,24,46,47,49,53,61$, and 74$)$ were unambiguously identified as ginsenoside $\mathrm{Rg}_{1}$, ginsenoside $R e$, ginsenoside $R_{2}$, ginsenoside $R b_{3}, 20 S$-ginsenoside $F_{1}$, ginsenoside $\mathrm{Rd}, 20 \mathrm{~S}$-ginsenoside $\mathrm{F}_{2}$, and 20S-ginsenoside $\mathrm{Rh}_{2}$. Unknown ginsenoside saponins followed the similar dissociation pathways. For the ginsenosides of protopanaxadiol, the ions at $m / z 407,425$, and 443 could be found in the positive ion mode. Meanwhile the ginsenosides of protopanaxatriol showed the ions at $\mathrm{m} / \mathrm{z} 405,423$, and 441 in the positive ion mode.

Ginsenoside $\mathrm{Rg}_{1}$ showed $[\mathrm{M}+\mathrm{Na}]^{+}$ion at $\mathrm{m} / z 823.4824$ $\left(\mathrm{C}_{42} \mathrm{H}_{72} \mathrm{O}_{14} \mathrm{Na}\right)$ in the positive ion mode and [M+HCOO] ion at $m / z 845.4895\left(\mathrm{C}_{43} \mathrm{H}_{73} \mathrm{O}_{16}\right)$ in the negative ion mode. The fragmentation ions at $m / z 621.4368$ and 603.4259 were produced from the protonated ion $[\mathrm{M}+\mathrm{H}]^{+}$by losing glucose and the further loss of $\mathrm{H}_{2} \mathrm{O}$. In the negative MS/MS analysis, $[\mathrm{M}-\mathrm{H}]^{-}$at $\mathrm{m} / z 799.4838$ gave the characteristic ion at $m / z$ 637.4307 [M-H-glc] ${ }^{-}$and $475.3773[\mathrm{M}-\mathrm{H}-2 \mathrm{glc}]^{-}$. Compounds $\mathbf{2 3}$ and $\mathbf{4 0}$ showed the quasimolecular ions at $\mathrm{m} / z 823[\mathrm{M}+\mathrm{Na}]^{+}$and $845[\mathrm{M}+\mathrm{HCOO}]^{-}$in the full mass spectrum. Compound $\mathbf{2 3}$ has the same retention time and MS data as those of reference ginsenoside $\mathrm{Rg}_{1}$ and it was identified as ginsenoside $\mathrm{Rg}_{1}$. As for compound 40, although the fragmentation ions at $\mathrm{m} / z 405,423$, or 441 could not be detected in the MS/MS spectrum, it was temporarily identified as ginsenoside $\mathrm{R}_{\mathrm{f}}$.

Ginsenoside Re showed $[\mathrm{M}+\mathrm{Na}]^{+}$ion at $\mathrm{m} / z 969.5427$ $\left(\mathrm{C}_{48} \mathrm{H}_{82} \mathrm{O}_{18} \mathrm{Na}\right)$ in the positive ion mode and [M+HCOO] ${ }^{-}$ ion at $m / z 991.5482\left(\mathrm{C}_{49} \mathrm{H}_{83} \mathrm{O}_{20}\right)$ in the negative ion mode. The fragmentation ions at $\mathrm{m} / z 945.5428[\mathrm{M}-\mathrm{H}]^{-}, 799.4845$ [M-H-rha $^{-}, 783.4893$ [M-H-glc $^{-}$, and 637.1430 [M-H-rhaglc] ${ }^{-}$were found in MS/MS spectrum in the negative ion mode. Compound 24 showed similar retention time and MS data as those of reference ginsenoside Re and it was identified as ginsenoside Re.

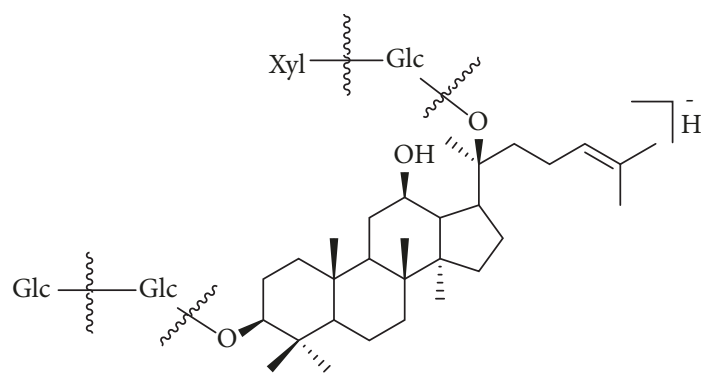

FIGURE 4: Proposed fragmentation pathway of ginsenoside $\mathrm{Rb}_{3}$.

As for reference ginsenoside $\mathrm{Rb}_{2},[\mathrm{M}+\mathrm{Na}]^{+}$ion at $\mathrm{m} / z$ $1101.5868\left(\mathrm{C}_{53} \mathrm{H}_{90} \mathrm{O}_{22} \mathrm{Na}\right)$ in the positive ion mode and $[\mathrm{M}+\mathrm{HCOO}]^{-}$ion at $m / z 1123.5908\left(\mathrm{C}_{54} \mathrm{H}_{91} \mathrm{O}_{24}\right)$ in the negative ion mode are shown in the full mass spectrum. The fragmentation ions at $m / z 945.5425$ [M-H-ara] ${ }^{-}$and 783.4889 $[\mathrm{M}-\mathrm{H} \text {-ara-glc }]^{-}$were detected in $\mathrm{MS}^{2}$. Reference ginsenoside $\mathrm{Rb}_{3}$ (Figure 4) gave the adduct ions at $m / z 1101.5844[\mathrm{M}+\mathrm{Na}]^{+}$ and $1123.5903[\mathrm{M}+\mathrm{HCOO}]^{-}$. The fragmentation ions at $\mathrm{m} / z$ 945.5430 [M-H-xyl] $]^{-}, 783.4881$ [M-H-xyl-glc $]^{-}$, and $\mathrm{m} / z$ 621.4352[M-H-xyl-2glc] ${ }^{-}$were observed in $\mathrm{MS}^{2}$.

Compounds 44, 46, and 47 have the same molecular formula of $\mathrm{C}_{53} \mathrm{H}_{90} \mathrm{O}_{22}$ according to the quasimolecular ions at $m / z 1101[\mathrm{M}+\mathrm{Na}]^{+}$and $1123[\mathrm{M}+\mathrm{HCOO}]^{-}$. Compounds 46 and 47 were unambiguously identified as ginsenoside $R b_{2}$ and ginsenoside $R b_{3}$ by comparing the retention time and MS data as those of references. Compound $\mathbf{4 4}$ was tentatively deduced as ginsenoside Rc.

$20 S$-ginsenoside $\mathrm{F}_{1}$ gave the adduct ions at $\mathrm{m} / z 661.4300$ $[\mathrm{M}+\mathrm{Na}]^{+} \quad\left(\mathrm{C}_{36} \mathrm{H}_{62} \mathrm{O}_{9} \mathrm{Na}\right)$ and $683.4375 \quad[\mathrm{M}+\mathrm{HCOO}]^{-}$ $\left(\mathrm{C}_{37} \mathrm{H}_{63} \mathrm{O}_{11} \mathrm{Na}\right)$. In the negative MS/MS experiment, the fragmentation ion at $m / z 475.3785$ [M-H-glc] $]^{-}$was detected. Compound 49 showed similar retention time and MS data as those of reference $20 S$-ginsenoside $\mathrm{F}_{1}$.

Reference ginsenoside $\mathrm{Rd}$ showed the adduct ions at $m / z 969.5379[\mathrm{M}+\mathrm{Na}]^{+}$and $991.5495[\mathrm{M}+\mathrm{HCOO}]^{-}$in the full mass spectrum. The fragmentation ions at $m / z 783.4892$ $[\mathrm{M}-\mathrm{H}-\mathrm{glc}]^{-}, 621.4368$ [M-H-2glc $^{-}$, and 459.3842 [M-H$3 \mathrm{glc}]^{-}$were produced by losing glucose. Compound 53 was 
identified as ginsenoside Rd by displaying the same retention time and MS information.

As for reference $20 \mathrm{~S}$-ginsenoside $\mathrm{F}_{2}$, it showed the quasimolecular ions at $\mathrm{m} / z 807.4890[\mathrm{M}+\mathrm{Na}]^{+}$and 829.4949 $[\mathrm{M}+\mathrm{HCOO}]^{-}$. The deprotonated ion peak at $\mathrm{m} / z 783.4881$ $[\mathrm{M}-\mathrm{H}]^{-}$produced the fragmentation ion at $\mathrm{m} / z 621.4355$ [M$\mathrm{H}$-glc] $]^{-}$in $\mathrm{MS}^{2}$. Compounds 45, 61, 64, and 65 gave the same adduct ions $[\mathrm{M}+\mathrm{Na}]^{+}$in positive $\mathrm{MS}$ and $[\mathrm{M}+\mathrm{HCOO}]^{-}$in negative MS, indicating the molecular formula as $\mathrm{C}_{42} \mathrm{H}_{72} \mathrm{O}_{13}$. Compound 45 was deduced as protopanaxatriol type and the latter three compounds were deduced as protopanaxadiol type on the base of the fragmentation rules described above. Among them, compound $\mathbf{6 1}$ has similar ions in full mass spectrum and MS/MS experiment as those of reference 20Sginsenoside $\mathrm{F}_{2}$ and was unambiguously identified as $20 \mathrm{~S}$ ginsenoside $\mathrm{F}_{2}$. The deprotonated ion of 45 at $\mathrm{m} / z 783.4910$ $[\mathrm{M}-\mathrm{H}]^{-}$indicated the ion at $\mathrm{m} / z 475.3791$ [M-H-rha-glc] $]^{-}$, supporting that 45 was ginsenoside $\mathrm{Rg}_{2}$. Compounds 64 and 65 displayed same MS data; however, unfortunately, $\mathrm{MS}^{2}$ information could not be detected and they were tentatively identified as $20 R$-ginsenoside $\mathrm{Rg}_{3}$ and 20S-ginsenoside $\mathrm{Rg}_{3}$.

Reference ginsenoside $\mathrm{Rh}_{2}$ showed the ions at $m / z \quad 1245.8995 \quad[2 \mathrm{M}+\mathrm{H}]^{+}, \quad 645.4348 \quad[\mathrm{M}+\mathrm{Na}]^{+}, \quad$ and $667.4437[\mathrm{M}+\mathrm{HCOO}]^{-}$. Compound 74 was identified as 20S-ginsenoside $\mathrm{Rh}_{2}$ by comparing the retention time and MS data.

Compounds 35, 36, and 37 have the same molecular formula of $\mathrm{C}_{48} \mathrm{H}_{82} \mathrm{O}_{19}$ and were tentatively characterized as 20S-glc-ginsenoside $\mathrm{R}_{\mathrm{f}}$, beads ginseng saponin $\mathrm{F}_{1}$, and notoginsenoside $\mathrm{R}_{3}$. They gave $[\mathrm{M}+\mathrm{Na}]^{+}$ions at $\mathrm{m} / \mathrm{z}$ 985.5332, 985.5319, and 985.5339 in the positive ion mode and $[\mathrm{M}+\mathrm{HCOO}]^{-}$ions at $m / z 1007.5457,1007.5457$, and 1007.5459 in the negative ion mode. In their MS/MS experiments, the fragmentation ions of $\mathbf{3 5}$ at $\mathrm{m} / z 799.4843$ and 637.4273 were produced from the ion at $\mathrm{m} / \mathrm{z} 961.5391[\mathrm{M}-\mathrm{H}]^{-}$by loss of glucose unit. Similarly, the fragmentation ions of 36 and 37 at $m / z 799$ and 637 were yielded. The retention order of three chromatographic peaks is determined according to the description in the literature [9].

The chemical formulas of compounds 42 and 43 are calculated as $\mathrm{C}_{41} \mathrm{H}_{70} \mathrm{O}_{13}$ based on the ions at $\mathrm{m} / \mathrm{z}$ $793.4705[\mathrm{M}+\mathrm{Na}]^{+}$in the positive ion mode and 815.4818 $[\mathrm{M}+\mathrm{HCOO}]^{-}$in the negative ion mode. Both compounds showed the fragmentation ions at $\mathrm{m} / z 405,423$, or 441 indicating that they are due to protopanaxatriol type. In MS/MS analysis, the ions at $m / z 637.4326[\mathrm{M}-\mathrm{H}-\mathrm{xyl}]^{-}$and 475.3794 [M-H-xyl-glc] $^{-}$for compound 42, as well as 637.4319 [M-Hara $]^{-}$and 475.3788 [M-H-ara-glc $]^{-}$for compound 43 , were detected from the deprotonated ions at $m / z 769.4753[\mathrm{M}-\mathrm{H}]^{-}$ and $769.4758[\mathrm{M}-\mathrm{H}]^{-}$, respectively. Compounds $\mathbf{4 2}$ and $\mathbf{4 3}$ were identified as notoginsenoside $\mathrm{R}_{2}$ and ginsenoside $\mathrm{F}_{3}$.

Compound 54 showed the quasimolecular ions at $\mathrm{m} / \mathrm{z}$ $939.5284[\mathrm{M}+\mathrm{Na}]^{+}$and $961.5390[\mathrm{M}+\mathrm{HCOO}]^{-}$, indicating the molecular formula as $\mathrm{C}_{47} \mathrm{H}_{80} \mathrm{O}_{17}$. The fragmentation ions 783.4901 [M-H-xyl $]^{-}$and 621.4363 [M-H-xyl-glc $]^{-}$were detected, supporting that $\mathbf{5 4}$ was gypenoside IX.

Compound 60 showed the quasimolecular ions at $\mathrm{m} / \mathrm{z}$ $789.4742[\mathrm{M}+\mathrm{Na}]^{+}$and $811.4871[\mathrm{M}+\mathrm{HCOO}]^{-}$and the molecular formula was calculated as $\mathrm{C}_{42} \mathrm{H}_{70} \mathrm{O}_{12}$. In the MS/MS analysis, the deprotonated ion at $\mathrm{m} / z$ 765.4792[M$\mathrm{H}]^{-}$gave the ions at $m / z 603.4261[\mathrm{M}-\mathrm{H}-\mathrm{glc}]^{-}$and 441.3730 $[\mathrm{M}-\mathrm{H}-2 \mathrm{glc}]^{-}$. Further loss of $\mathrm{H}_{2} \mathrm{O}$ yielded the ions at $\mathrm{m} / z 423$ and 405 . It was identified as ginsenoside $\mathrm{Rk}_{1}$.

Compound 34 showed $[\mathrm{M}+\mathrm{Na}]^{+}$ion at $\mathrm{m} / z 1117.5740$ and $[\mathrm{M}+\mathrm{HCOO}]^{-}$ion at $\mathrm{m} / z$ 1139.5891, suggesting the molecule formula of $\mathrm{C}_{53} \mathrm{H}_{90} \mathrm{O}_{23}$. Besides, it showed [M$\mathrm{H}]^{-}$ion at $\mathrm{m} / \mathrm{z} 1093.5826$ and fragment ions at $\mathrm{m} / \mathrm{z} 961$ $[\mathrm{M}-\mathrm{H}-\mathrm{xyl} / \mathrm{ara}]^{-}, 799$ [M-H-xyl/ara-glc $]^{-}$, and $637[\mathrm{M}-\mathrm{H}-$ $\mathrm{xyl} / \mathrm{ara}-2 \mathrm{glc}]^{-}$, concerning consecutive loss of 132, 294, and 456. These data were in accordance with those of floral ginsenoside $\mathrm{P}$, floranotoginsenoside $\mathrm{D}$, notoginsenoside $\mathrm{FT}_{3}$, or yesanchinoside $\mathrm{H}$ [9], but its structure was not accurately determined based on the limited information.

Compound 72 showed $[\mathrm{M}+\mathrm{Na}]^{+}$ion at $\mathrm{m} / \mathrm{z} 789.4742$ and $[\mathrm{M}+\mathrm{HCOO}]^{-}$ion at $\mathrm{m} / \mathrm{z} 811.4847$, indicating the molecule formula as $\mathrm{C}_{42} \mathrm{H}_{70} \mathrm{O}_{12}$. Besides, the ions at $\mathrm{m} / z 603.4251$ [M-H-162 $]^{-}$and 471.3466 [M-H-162-132 $^{-}$in the MS/MS analysis suggested that the glycoside chain of $\mathbf{7 2}$ consisted of a molecule of glucose and a molecule of arabinose or xylose. It could be one of ilexoside A or ilexoside D described in the literature [10].

Flavonoids. Flavonoids always present high sensitivity in the UV spectra. They could be well detected in both positive and negative ionization modes. Rutin, which has UV $\lambda_{\max }$ absorption at 255 and $353 \mathrm{~nm}$, showed the protonated ion at $\mathrm{m} / z 611.1656[\mathrm{M}+\mathrm{H}]^{+}$and deprotonated ion at $\mathrm{m} / \mathrm{z}$ $609.1461[\mathrm{M}-\mathrm{H}]^{-}$as well as the ion at $\mathrm{m} / z 1219.3008$ [2M$\mathrm{H}]^{-}$. Quercetin, with UV $\lambda_{\max }$ absorption at 253 and 356 $\mathrm{nm}$, displayed the deprotonated ion at $\mathrm{m} / z 301.0376$ [M$\mathrm{H}]^{-}$. Four compounds $(9,10,13$, and 26) were determined as flavonoid derivatives due to the typical UV absorption. Especially, compound 9 was one of main constituents of XXT. Compounds 9 and $\mathbf{2 6}$ were unambiguously identified as rutin and quercetin based on the direct comparison of their UV spectra, and mass spectra with those of the authentic compounds. Compound $\mathbf{1 0}$ has UV $\lambda_{\max }$ absorption at 264 and $343 \mathrm{~nm}$. The molecular formula was calculated as $\mathrm{C}_{27} \mathrm{H}_{30} \mathrm{O}_{15}$ by the quasimolecular ion at $\mathrm{m} / z 595.1652$ $[\mathrm{M}+\mathrm{H}]^{+}, 617.1472[\mathrm{M}+\mathrm{Na}]^{+}$, and $593.1505[\mathrm{M}-\mathrm{H}]^{-}$. Other fragment ions at $\mathrm{m} / z$ 449.1083 $[\mathrm{M}+\mathrm{H}-\mathrm{rha}]^{+}$and 287.1055 $[\mathrm{M}+\mathrm{H} \text {-rha-glc }]^{+}$were detected. Therefore, compound $\mathbf{1 0}$ was identified as kaempferol-3-O-rutinoside. Compound $\mathbf{1 3}$ has UV $\lambda_{\max }$ absorption at 252 and $339 \mathrm{~nm}$. The molecular formula was calculated as $\mathrm{C}_{28} \mathrm{H}_{32} \mathrm{O}_{16}$ by the quasimolecular ion at $m / z 625.1754[\mathrm{M}+\mathrm{H}]^{+}, 647.1578[\mathrm{M}+\mathrm{Na}]^{+}$, and 623.1616 $[\mathrm{M}-\mathrm{H}]^{-}$, suggesting it was isorhamnetin 3-O-rutinoside [11].

Phenolic acids. Phenolic acids are the main constituents of XXT. This category of compounds was primarily derived from the ingredient herb, Salviae miltiorrhizae radix et rhizoma and Hairy holly root. In this study, 14 phenolic acids were found, among which 10 compounds $(1,2,4,5,7,11,14$, 15,16 , and 22) were identified as danshensu, neochlorogenic acid, chlorogenic acid, protocatechuic aldehyde, caffeic acid, isochlorogenic acid $\mathrm{A}$, isochlorogenic acid $\mathrm{B}$, isochlorogenic acid $\mathrm{C}$, rosmarinic acid, and salvianolic acid B by using reference substances. Other compounds (12, 17, 18, and 32) were tentatively characterized by comparing UV absorption, 
retention time, molecular formula, and mass fragmentation pathways [12-14].

Danshensu has UV $\lambda_{\max }$ absorption at $279 \mathrm{~nm}$ and retention time at $1.03 \mathrm{~min}$. It showed the precursor ion at $\mathrm{m} / z 197.0443$ and the molecular formula was calculated as $\mathrm{C}_{9} \mathrm{H}_{10} \mathrm{O}_{5}$. In the full mass spectrum, the $[2 \mathrm{M}-\mathrm{H}]^{-}$ion at $\mathrm{m} / z 395.07949$ was found. The MS/MS spectrum of [M$\mathrm{H}]^{-}$exhibited an obvious fragment ion, $\left[\mathrm{M}-\mathrm{H}-\mathrm{H}_{2} \mathrm{O}\right]^{-}$at $\mathrm{m} / z$ 179.0338, and further loss of $\mathrm{COOH}$ obtained ion at $\mathrm{m} / z$ 135.0438. Compound $\mathbf{1}$ was identified as danshensu.

Neochlorogenic acid has UV $\lambda_{\text {max }}$ absorption at $323 \mathrm{~nm}$. In the full mass spectrum, the deprotonated ion at $\mathrm{m} / z$ $353.0869[\mathrm{M}-\mathrm{H}]^{-}$was found. The MS/MS spectrum of $[\mathrm{M}-$ $\mathrm{H}]^{-}$showed ions at $m / z 191.0548,179.0336$, and 135.0438 . Compound 2 was identified as neochlorogenic acid.

Chlorogenic acid has UV $\lambda_{\max }$ absorption at $325 \mathrm{~nm}$ and showed the quasimolecular ion at $m / z 353.0872[\mathrm{M}-\mathrm{H}]^{-}$and $707.1482[2 \mathrm{M}-\mathrm{H}]^{-}$. The fragment ion at $m / z 191.0553$ was yielded by losing $\mathrm{C}_{9} \mathrm{H}_{6} \mathrm{O}_{3}$. Compound 4 was identified as chlorogenic acid.

Protocatechuic aldehyde has UV $\lambda_{\max }$ absorption at 229, 278 , and $310 \mathrm{~nm}$. The $[\mathrm{M}-\mathrm{H}]^{-}$ion at $\mathrm{m} / z 137.0236$ was detected. In the MS/MS analysis, the ion at $m / z 108.0204$ was yielded by losing $\mathrm{CHO}$ and further losing oxygen produced from the ion at $m / z$ 92.0256. Compound $\mathbf{5}$ was identified as protocatechuic aldehyde.

Caffeic acid has UV $\lambda_{\max }$ absorption at 238 and $322 \mathrm{~nm}$. It showed $[\mathrm{M}-\mathrm{H}]^{-}$ion at $\mathrm{m} / z 179.0339$ in the full mass spectrum and the ion at $m / z 135.0438$ by losing $\mathrm{CO}_{2}$ in the MS/MS experiment. Compound 7 was identified as caffeic acid.

The parent ions of three compounds $(\mathbf{1 1}, \mathbf{1 4}$, and 15) at $m / z 515[\mathrm{M}-\mathrm{H}]^{-}$and $517[\mathrm{M}+\mathrm{H}]^{+}$were easily located in the chromatogram of XXT, suggesting the molecular formula of $\mathrm{C}_{25} \mathrm{H}_{24} \mathrm{O}_{12}$. They were assigned as dicaffeoylquinic acids by comparison with retention times. Besides, they gave the same fragment ions with those of chlorogenic acid, such as $\mathrm{m} / \mathrm{z} 191$, 179,173 , and 135. in MS/MS experiments. The fragmentation pathways are in accordance with those described in the literature [15]. Therefore, compounds 11, 14, and 15 were isochlorogenic acid $\mathrm{B}, \mathrm{A}$, and $\mathrm{C}$.

Rosmarinic acid included a caffeic acid moiety and a molecule of danshensu. It showed $[\mathrm{M}-\mathrm{H}]^{-}$ion at $\mathrm{m} / \mathrm{z}$ 359.0759. The fragment ions at $m / z 197.040$ and 179.0332 were yielded by losing caffeic acid or danshensu moiety in $\mathrm{MS}^{2}$. Besides, the ion at $m / z 161.0231$ was yielded by further loss of $\mathrm{H}_{2} \mathrm{O}$. Compound $\mathbf{1 6}$ was identified as rosmarinic acid.

Salvianolic acid B showed $[\mathrm{M}-\mathrm{H}]^{-}$ion at $m / z$ 717.1464. Besides, the fragment ions at $m / z \quad 519.0934$ ([M-H$\left.\mathrm{C}_{9} \mathrm{H}_{10} \mathrm{O}_{5}\right]^{-}$), 339.0504, and 321.0392 were detected in the MS/MS analysis. The characteristic fragmentation pathway of losing $\mathrm{C}_{9} \mathrm{H}_{10} \mathrm{O}_{5}$ is in accordance with those described in the literature [16]. Based on the retention time and the mass fragmentation pathway, compound 22 was identified as salvianolic acid B.

Compound 12 has UV $\lambda_{\max }$ absorption at 244 and 327 $\mathrm{nm}$. The molecular formula was calculated as $\mathrm{C}_{27} \mathrm{H}_{22} \mathrm{O}_{12}$ on the basis of the quasimolecular ions at $m / z 539.1149[\mathrm{M}+\mathrm{H}]^{+}$ and $537.1031[\mathrm{M}-\mathrm{H}]^{-}$. In the MS/MS experiment, it indicated the characteristic ion at $m / z 339.0500\left[\mathrm{M}-\mathrm{H}-\mathrm{C}_{9} \mathrm{H}_{10} \mathrm{O}_{5}\right]^{-}$, supporting that compound $\mathbf{1 2}$ was salvianolic acid $\mathrm{H}$.

Compound $\mathbf{1 7}$ has UV $\lambda_{\max }$ absorption at 250 and 306 $\mathrm{nm}$. It showed the ion at $\mathrm{m} / z 341.0666[\mathrm{M}+\mathrm{H}]^{+}$. In the MS/MS analysis, the ions at $\mathrm{m} / z 295.0617$ and 279.0659 were yielded by losing $\mathrm{CH}_{2} \mathrm{O}_{2}$ and $\mathrm{CH}_{2} \mathrm{O}_{3}$. Compound 17 was identified as salvianolic acid $\mathrm{G}$.

Compound $\mathbf{1 8}$ has UV $\lambda_{\max }$ absorption at 251 and 317 $\mathrm{nm}$. It showed $[\mathrm{M}-\mathrm{H}]^{-}$ion at $\mathrm{m} / z 493.1134$ and the molecular formula was calculated as $\mathrm{C}_{26} \mathrm{H}_{22} \mathrm{O}_{10}$. In the MS/MS analysis, the fragment ion at $m / z 295.0604\left[\mathrm{M}-\mathrm{H}-\mathrm{C}_{9} \mathrm{H}_{10} \mathrm{O}_{5}\right]^{-}$was detected, suggesting compound 18 was salvianolic acid A.

Compound 32 showed the ions at $m / z 567.1498[\mathrm{M}+\mathrm{H}]^{+}$, $589.1320[\mathrm{M}+\mathrm{Na}]^{+}$, and $565.1342[\mathrm{M}-\mathrm{H}]^{-}$in MS spectrum, revealing molecular formula of $\mathrm{C}_{29} \mathrm{H}_{26} \mathrm{O}_{12}$. Besides, fragment ion at $\mathrm{m} / z$ 369.0971 [M-H- $\left.\mathrm{C}_{9} \mathrm{H}_{10} \mathrm{O}_{5}\right]^{-}$was observed. Compound 32 was identified as ethyl lithospermate.

Bufadienolides. The MS/MS behaviors of bufadienolides have been extensively described [17, 18]. Briefly, for bufadienolides with only hydroxyl substituents, the fragmentation was characterized by successive eliminations of $\mathrm{H}_{2} \mathrm{O}$ and $\mathrm{CO}$ molecules, and the profile of MS/MS product ions was correlated with the number of hydroxyl groups. If a C-16 acetoxyl group was present, the fragmentation of $[\mathrm{M}+\mathrm{H}]^{+}$ ions was triggered by initial loss of $60 \mathrm{Da}$ (HOAc). The elimination of $\mathrm{CO}$ was significant for bufadienolides with a 19-formyl group, and the 19-hydroxyl group could be characterized by the loss of $30 \mathrm{Da}$ (HCHO). These fragmentation rules were applied to the identification of bufadienolides in XXT sample. As shown in Table 1, eight bufadienolides were screened from XXT, six of which were unambiguously identified as gamabufotalin (19), arenobufagin (25), bufotalin (41), bufalin (50), resibufogenin (55), and cinobufagin (56) by comparison with reference substances isolated from toad venom. The other two bufadienolides were tentatively identified as bufarenogin (20) and hellebrigenin (29) [18, 19]. Taking gamabufotalin as a case, the fragmentation rules of bufadienolides were explained (Figure 5). Gamabufotalin showed UV $\lambda_{\max }$ absorption at $295 \mathrm{~nm}$. In its full mass spectrum, $[\mathrm{M}+\mathrm{H}]^{+}$ion at $m / z 403.2486$ was found and the fragment ions at $m / z 385.2366\left[\mathrm{M}+\mathrm{H}-\mathrm{H}_{2} \mathrm{O}\right]^{+}, 367.2262$ $\left[\mathrm{M}+\mathrm{H}-2 \mathrm{H}_{2} \mathrm{O}\right]^{+}$, and $349.2169\left[\mathrm{M}+\mathrm{H}-3 \mathrm{H}_{2} \mathrm{O}\right]^{+}$were detected in $\mathrm{MS}^{2}$.

Bile acids. Bile acid derivatives are in lack of conjugated system and their UV absorption is not obvious. However, they always present high sensitivity in the negative ion mode. The deprotonated ion $[\mathrm{M}-\mathrm{H}]^{-}$and adduct ion $[\mathrm{M}+\mathrm{HCOO}]^{-}$ were obviously detected in MS spectrum. The loss of side chain was commonly observed in $\mathrm{MS}^{2}$. Four bile acid derivatives were detected from XXT sample, two of which were unambiguously identified as ursodeoxycholic acid (58, UDCA) and chenodeoxycholic acid (70, CDCA) based on the direct comparison of reference substances. The other two compounds were tentatively identified as cholanic acid (57) and hyodeoxycholic acid (67). They are derived from the raw material, Rengong Niuhuang (Bovis calculus artifactus) [20].

Ursodeoxycholic acid showed the ions at $\mathrm{m} / \mathrm{z} 391.2851$ $[\mathrm{M}-\mathrm{H}]^{-}, 437.2916[\mathrm{M}+\mathrm{HCOO}]^{-}$, and $783.5778[2 \mathrm{M}-\mathrm{H}]^{-}$in 


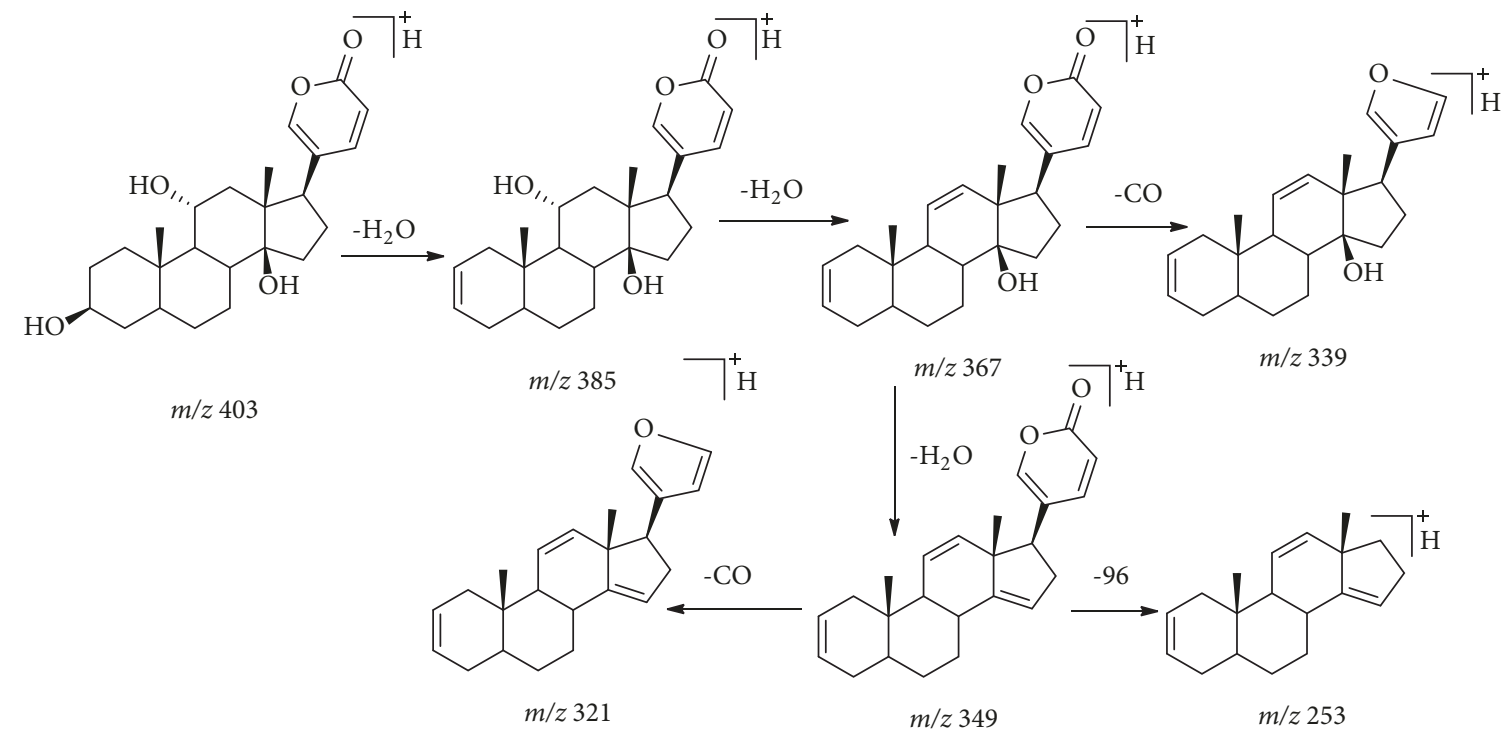

FIGURE 5: Proposed fragmentation pathway of gamabufotalin.

the negative ion mode. In the positive ion mode, the ion at $m / z 357.2807\left[\mathrm{M}+\mathrm{H}-2 \mathrm{H}_{2} \mathrm{O}\right]^{+}$was assigned as the loss of two molecules of $\mathrm{H}_{2} \mathrm{O}$. The ion at $\mathrm{m} / z 321.2587$ represented its side chain loss in $\mathrm{MS}^{2}$. Compound $\mathbf{5 8}$ was identified as UDCA.

CDCA showed the ions at $m / z \quad 391.2872$ [M-H] $^{-}$, $437.2907\left[\mathrm{M}+\mathrm{HCOO}^{-}\right.$, and $783.5798[2 \mathrm{M}-\mathrm{H}]^{-}$in the negative ion mode. In the positive ion mode, the loss of $\mathrm{H}_{2} \mathrm{O}$ unit yielded $\left[\mathrm{M}+\mathrm{H}-2 \mathrm{H}_{2} \mathrm{O}\right]^{+}$ion at $m / z$ 357.2809. The occurrence of the ion at $m / z 321.2586$ in $\mathrm{MS}^{2}$ was due to side chain loss. Compound 70 was identified as CDCA.

Compound 57 showed $[\mathrm{M}+\mathrm{Na}]^{+}$ion at $\mathrm{m} / z 431.2778$ in positive mode, and $[\mathrm{M}-\mathrm{H}]^{-}$ion at $m / z$ 407.2803, $\left.{ }^{\mathrm{M}+\mathrm{HCOO}}\right]^{-}$ion at $\mathrm{m} / z$ 453.2857, and $[2 \mathrm{M}-\mathrm{H}]^{-}$ion at $\mathrm{m} / \mathrm{z}$ 815.5698 in the negative mode. The ions representing a series of $\mathrm{H}_{2} \mathrm{O}$ loss was observed, such as $373.2749\left[\mathrm{M}+\mathrm{H}-2 \mathrm{H}_{2} \mathrm{O}\right]^{+}$ and $355.2649\left[\mathrm{M}+\mathrm{H}-3 \mathrm{H}_{2} \mathrm{O}\right]^{+}$. It was tentatively characterized as cholanic acid.

Compound 67 showed $[\mathrm{M}-\mathrm{H}]^{-}$ion at $m / z$ 391.2852, $[\mathrm{M}+\mathrm{HCOO}]^{-}$ion at $\mathrm{m} / z$ 437.2903, and $[2 \mathrm{M}-\mathrm{H}]^{-}$at $\mathrm{m} / z$ 783.5792 in the full mass spectrum. The molecular formula was calculated as $\mathrm{C}_{24} \mathrm{H}_{40} \mathrm{O}_{4}$. It was tentatively deduced as hyodeoxycholic acid.

Quinones derivatives. Quinones derivatives are another kind of active constituents from Danshen and they were easily detected in XXT sample. Compounds 63, 71, and 76 were identified as dihydrotanshinone, cryptotanshinone, and tanshinone II A by comparison with reference substances. They displayed similar fragmentation pathways concerning successive eliminations of $\mathrm{H}_{2} \mathrm{O}$ and $\mathrm{CO}$ molecules. Tanshinone IIA was used as an example to illustrate the fragmentation pathway of quinones constituents as shown in Figure 6. Based on these rules as well as empirical molecular formula, 7 compounds were characterized as tanshindiol A 31, 1-oxo tanshinone IIA 59, neotanshinone D 62, tetrahydrotanshinone I 66, methyltanshinonate 69, methylenetanshinquinone 73 , and miltirone 77 . [12, 16, 20, 21].
Phthalide derivative. Compound $\mathbf{2 1}$ has UV absorption at $276 \mathrm{~nm}$. Its molecular formula was calculated as $\mathrm{C}_{12} \mathrm{H}_{14} \mathrm{O}_{3}$ on the basis of $[\mathrm{M}+\mathrm{H}]^{+}$ion at $m / z 207.1024$. The above data were in accordance with those of 4-hydroxyl-3-butylphthalide in the literature [22]. Compound $\mathbf{2 1}$ was tentatively assigned as 4-hydroxyl-3-butylphthalide. It could be derived from individual herb Chuanxiong rhizome [23].

Among the identified compounds, most constituents were derived from the raw materials, Danshen and Renshen Jingye Zongzaogan, and a small proportion of compounds were considered from Huaihua, Maodongqing, Chuanxiong, Chansu, and Rengong Niuhuang. The other ingredients, Rengong Shexiang, Bingpian, and Shuizhi, were not characterized in the present HPLC and UPLC-QTOF/MS condition. This could be related to the prescription of raw materials and the manufacturing process employed. Usually, muscone, one of active constituents in Rengong Shexiang and borneol are detected by GC or GC-MS [3]. They are not easily detected in the liquid chromatography. Additionally, it is worth noting that no chemical information of Shuizhi, a famous traditional Chinese medicine originated from animal source, was found, although small molecule compounds with diverse structures have been reported from this drug [24]. More effort is made to explain its prescription role in XXT product.

\section{Conclusion}

In this work, HPLC analysis was employed to find out the common chromatographic peak in various batches of XXT samples and UPLC-Q-TOF/MS was used for the identification of main constituents in the typical XXT sample. As a result, a total of 63 constituents including twenty saponins, four flavonoids, fifteen phenolic acids, eight steroids, four bile acids, ten quinones, and other two compounds were identified or tentatively characterized based on the comparison of retention time and UV spectra with authentic compounds as well as by summarized MS fragmentation 
<smiles>C=CC1=Cc2ccc3c(c2C(=O)C1)CCCC3(C)C</smiles>

$m / z 266$<smiles></smiles><smiles>C=Cc1cc2ccc3c(CC)c4cc1-c2c34</smiles>

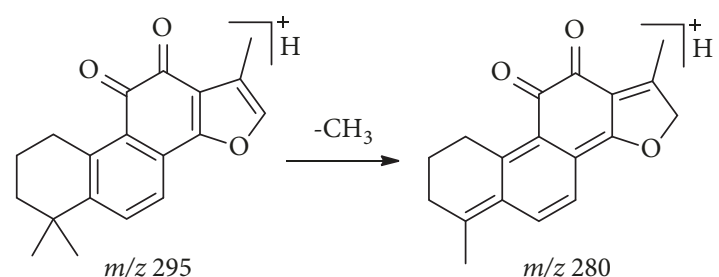

$m / z 295$<smiles>COCCO</smiles><smiles>C[I+]c1coc2c1C(=O)C=c1c-2ccc2c1=CCCC2(C)C</smiles>
$m / z 277$

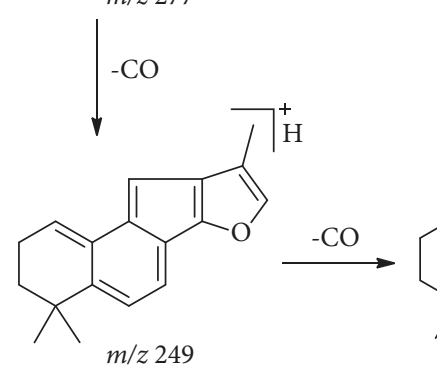
$m / z 249$<smiles>[3H][13CH2][13CH2][13CH3]</smiles>

Figure 6: Proposed fragmentation pathway of tanshinone IIA.

rules and matching empirical molecular formula with those of published components. The present investigation clearly understood the nonvolatile constituents in XXT and provided good basis for further study on the active substances and quality control of this preparation.

\section{Data Availability}

HPLC and UPLC-ESI-Q-TOF/MS data used to support the findings of this study are available from the corresponding author upon request.

\section{Conflicts of Interest}

The authors declare that they have no conflicts of interest.

\section{Acknowledgments}

This work was financially supported by NSFC (81773897), Standardization Project of Chinese Medicines (ZYBZH-CJL-25), and the Fundamental Research Funds for the Central Public Welfare Research Institutes (QZPT004). The first author is thankful to Beijing Municipal Education Commission for providing a bachelor degree project (JWX201707).

\section{Supplementary Materials}

The pharmaceutical manufacture process of XXT described in current Chinese Pharmacopoeia is shown in Figure S1.
HPLC of XXT sample and extract of each raw material at 251 $\mathrm{nm}$ are shown Figure S2. Relative retention time ratio and relative area ratio of common characteristic peaks in precision, repeatability, and stability test for the HPLC method validation are shown in Tables S1 S6. (Supplementary Materials)

\section{References}

[1] Y. Li, Y.-M. Xie, Y. Liu, and W. Zhao, "Explore Xueshuan Xinmaining tablet effecting on treatment outcome of coronary heart disease based on propensity score," Zhongguo Zhong yao za $z$ hi $=$ Zhongguo zhongyao zazhi = China journal of Chinese materia medica, vol. 40, no. 24, pp. 4791-4796, 2015.

[2] Chinese Pharmacopoeia Commission, Chinese Pharmacopoeia, China Medical Science Press, Beijing, China, 2015.

[3] J. P. Liu, L. Ming, H. Y. Liu et al., "Chemical constituents in volatile oil from Xueshuan Xinmaining Tablet with GC-MS analysis," Chinese Journal of Experimental Traditional Medical Formulae, vol. 18, no. 15, pp. 93-95, 2012.

[4] L. Ming, M. Y. Lin, Q. H. Zhang et al., "Fingerprint of Xueshuan Xinmaining Tablet by HPLC-ELSD," China Pharmacy, vol. 24, no. 7, pp. 639-641, 2013.

[5] H. J. Hu, L. F. Lin, Y. L. Liu et al., "Study on UPLC-PDA fingerprint of Xueshuan Xinmaining Tablets," Chinese Traditional and Herbal Drugs, vol. 48, no. 20, pp. 4268-4274, 2017.

[6] H. Li, Y. Yu, Z. Wang et al., "Chemical Profiling of Re-DuNing Injection by Ultra-Performance Liquid Chromatography Coupled with Electrospray Ionization Tandem Quadrupole Time-of-Flight Mass Spectrometry through the Screening of 
Diagnostic Ions in MSE Mode," PLoS ONE, vol. 10, no. 4, p. e0121031, 2015.

[7] Y.-J. Wei, P. Li, B. Shu et al., "Analysis of chemical and metabolic components in traditional Chinese medicinal combined prescription containing Radix Salvia miltiorrhiza and Radix Panax notoginseng by LC-ESI-MS methods," Biomedical Chromatography, vol. 21, no. 8, pp. 797-809, 2007.

[8] J. F. Guo, D. F. Zhong, S. Y. Qiao, and Y. M. Zhao, "Analysis of ginsenosides by liquid chromatography-electrospray mass spectrometry," Journal of Chinese Mass Spectrometry Society, vol. 24, no. 4, pp. 477-481, 2003.

[9] L.-W. Qi, C.-Z. Wang, and C.-S. Yuan, "Isolation and analysis of ginseng: Advances and challenges," Natural Product Reports, vol. 28, no. 3, pp. 467-495, 2011.

[10] Z. L. Zhou, J. L. Li, and Z. L. Yang, "Rapid analysis of absorption ingredients of triterpenoidic saponins in Ilex pubescens using electrospray ionization multi-stage mass spectrometry combined with everted intestinal sac method," Natural Product Research and Development, vol. 25, no. 8, pp. 1115-1119, 2013.

[11] R. Li, C. Wang, P. Lei, L. Huang, and S. Yuan, "Chemical constituents in flos sophorae carbonisatus," Zhongguo Zhongyao Zazhi, vol. 35, no. 5, pp. 607-609, 2010.

[12] X. Dong, L. Xu, and Z.-Y. Lou, "Determination of chemical components from Salvia miltiorrhiza bunge by electrospray ion-trap mass spectrometry," Chinese Pharmaceutical Journal, vol. 45, no. 14, pp. 1048-1054, 2010.

[13] Y. Liu, Z. Song, and Y. Zhang, "Application of Plackett-BurmanCentral composite design for fingerprint analysis of $\mathrm{Gu}-$ Chang-Zhi-Xie pill by HPLC-DAD approach," Modern Chinese Medicine, vol. 17, pp. 590-595, 2015.

[14] H. L. Wang, W. Qi, X. D. Wu, and Z. M. He, "Fragmentation mechanisms of phenolic acids from Danshen in an ion trap by electrospray ionization multi-stage tandem mass spectrometry," Journal of Chinese Mass Spectrometry Society, vol. 29, no. 3, pp. 129-136, 2008.

[15] L.-W. Qi, C.-Y. Chen, and P. Li, "Structural characterization and identification of iridoid glycosides, saponins, phenolic acids and flavonoids in Flos Lonicerae Japonicae by a fast liquid chromatography method with diode-array detection and timeof-flight mass spectrometry," Rapid Communications in Mass Spectrometry, vol. 23, no. 19, pp. 3227-3242, 2009.

[16] Z. J. Guo, L. H. Long, Y. Xu, Y. Zhang, and X. Tang, "Analysis of liposoluble, water soluble compounds in Salvia miltiorrhiza by UPLC-ESI-ESI (in Chinese," Journal of Chinese Medicinal Materials, vol. 33, no. 6, pp. 925-929, 2010.

[17] M. Ye and D.-A. Guo, "Analysis of bufadienolides in the Chinese drug ChanSu by high-performance liquid chromatography with atmospheric pressure chemical ionization tandem mass spectrometry," Rapid Communications in Mass Spectrometry, vol. 19, no. 13, pp. 1881-1892, 2005.

[18] H. Gao, M. Zehl, A. Leitner, X. Wu, Z. Wang, and B. Kopp, "Comparison of toad venoms from different Bufo species by HPLC and LC-DAD-MS/MS," Journal of Ethnopharmacology, vol. 131, no. 2, pp. 368-376, 2010.

[19] Y.-M. Wang, Z.-Y. Li, J.-J. Wang, X.-Y. Wu, H.-M. Gao, and Z.M. Wang, "Bufadienolides and polyhydroxycholestane derivatives from Bufo bufo gargarizans," Journal of Asian Natural Products Research, vol. 17, no. 4, pp. 364-376, 2015.

[20] D. Chen, S. Lin, W. Xu et al., "Qualitative and quantitative analysis of the major constituents in Shexiang Tongxin dropping pill by HPLC-Q-TOF-MS/MS and UPLC-QqQ-MS/MS," Molecules, vol. 20, no. 10, pp. 18597-18619, 2015.
[21] J. Liu, H. H. Yang, F. S. C. Lee, and X. R. Wang, "Analysis of diterpene quinones in Danshen (Salvia Miltiorrhiza Bunge) by HPLC-ESI-TOF/MS," Journal of Chinese Mass Spectrometry Society, vol. 29, no. 5, pp. 261-267, 2008.

[22] J. J. Liang, H. M. Gao, L. M. Chen et al., "Chemical profiling of an anti-migraine herbal preparation, Tianshu Capsule, based on the combination of HPLC, LC-DAD-MSn, and LC-DADESI-IT-TOFMS analyses," Evidence-Based Complementary and Alternative Medicine, vol. 2014, Article ID 580745, 2014.

[23] X. F. Xu, D. D. Sun, X. Li, J. W. Chen, and J. C. Cui, "Analysis on chemical components from water extract of Ligusticum Chuanxiong by UPLC-ESI-Q-TOF-MS," Journal of Nanjing University of Traditional Chinese Medicine, vol. 29, no. 4, pp. 382-386, 2013.

[24] H. Dong, J. X. Ren, J. J. Wang, L. S. Ding, S. Y. Zhao, and H. M. Gao, "Chinese Medicinal Leech: Ethnopharmacology, Phytochemistry, and Pharmacological Activities," Evidence-Based Complementary and Alternative Medicine, vol. 2016, Article ID 7895935, 11 pages, 2016. 


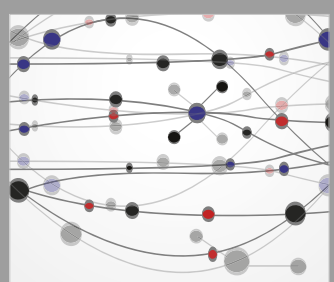

The Scientific World Journal
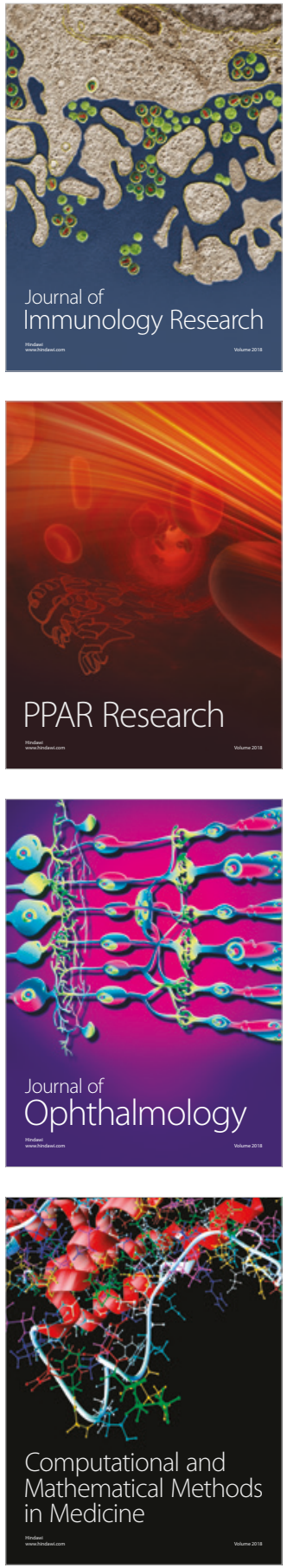

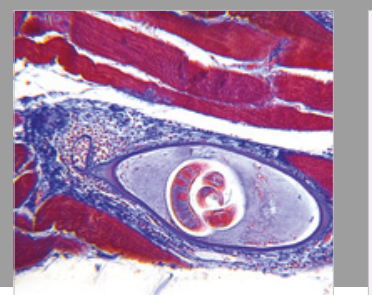

Gastroenterology Research and Practice

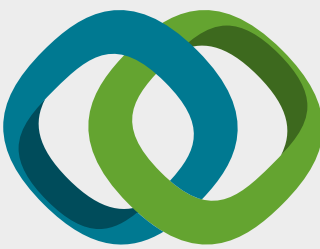

\section{Hindawi}

Submit your manuscripts at

www.hindawi.com
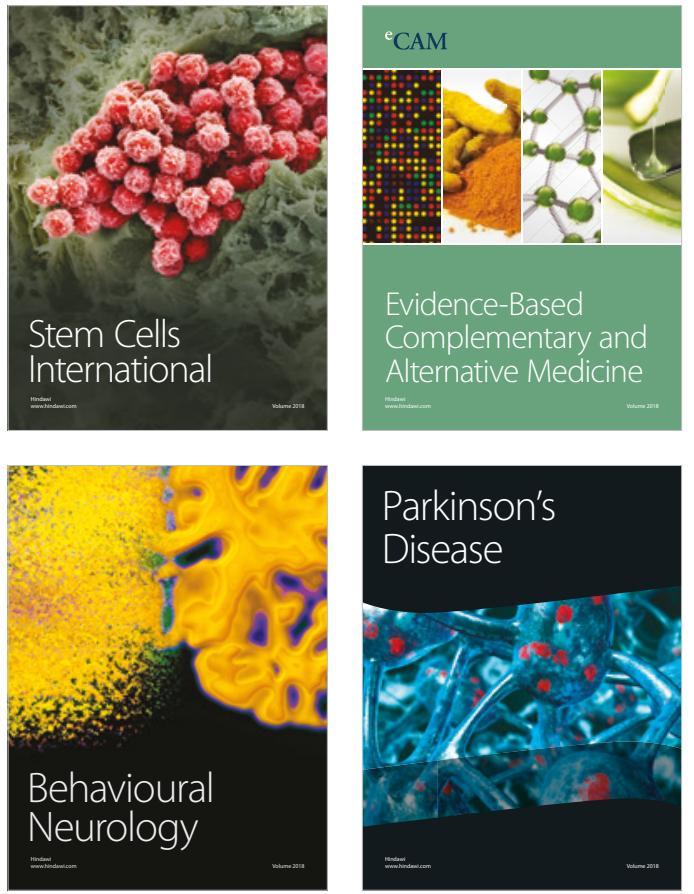

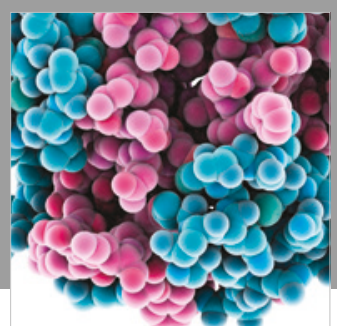

ournal of

Diabetes Research

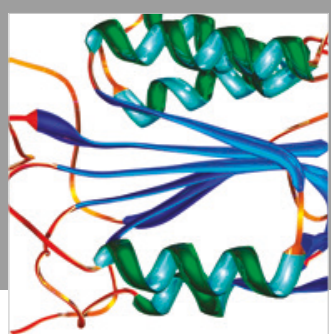

Disease Markers
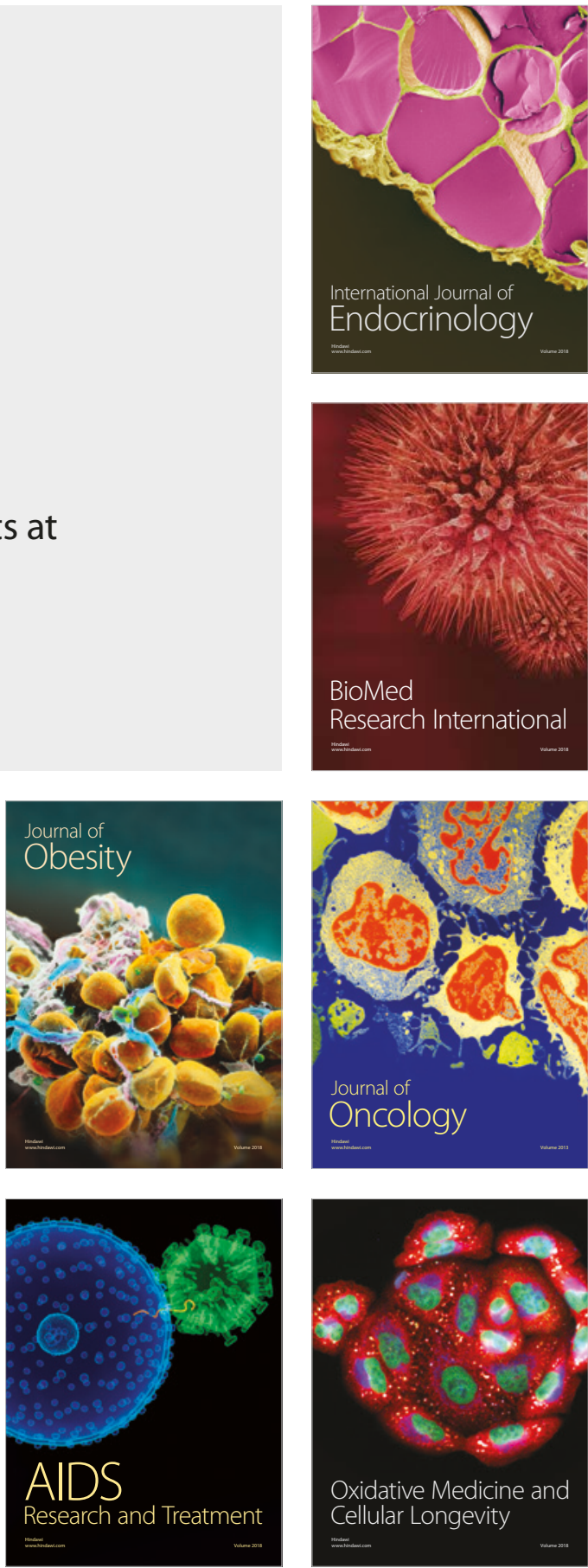